\title{
A fatal case of Trichosporon asahii fungemia and pneumonia in a kidney transplant recipient during caspofungin treatment
}

This article was published in the following Dove Press journal:

Therapeutics and Clinical Risk Management

30 September 2014

Number of times this article has been viewed

\section{Mei-fang Yang ${ }^{1,2}$ \\ Hai-nv Gao',2 \\ Lan-juan $\mathrm{Li}^{1,2}$}

'State Key Laboratory for Diagnosis and Treatment of Infectious Diseases, The First Affiliated Hospital, School of Medicine, Zhejiang University; ${ }^{2}$ Collaborative Innovation Center for Diagnosis and Treatment of Infectious Diseases, Hangzhou, People's Republic of China
Correspondence: Lan-juan Li State Key Laboratory for Diagnosis and Treatment of Infectious Diseases, The First Affiliated Hospital School of Medicine, Zhejiang University, 79 Qingchun Road, Hangzhou 310003. People's Republic of China Tel +86I 390 65I 4210 Email ljli@zju.edu.cn

\begin{abstract}
Trichosporon asahii is an emerging opportunistic pathogen that is life-threatening particularly for immunosuppressed patients. Only a few studies have described Trichosporon infection in kidney transplant recipients. This study reports a 67-year-old male kidney transplant recipient who developed fatal fungemia and pneumonia caused by T. asahii during caspofungin treatment. Although funguria is benign, kidney transplant recipients are still at risk of T. asahii fungemia and invasive T. asahii infection even if they are under antifungal therapy, particularly echinocandins.
\end{abstract}

Keywords: funguria, organ transplant, opportunistic infection, invasive fungal infection, antifungal therapy

\section{Background}

Trichosporon asahii (formerly known as T. beigelii) is a rare opportunistic pathogen associated with severe complications, particularly in immunosuppressed patients. ${ }^{1}$ To our knowledge, only a few studies have described Trichosporon infection in kidney transplant recipients. ${ }^{2-7}$ This study presents a 67 -year-old male with an 8-year history of kidney transplantation who developed $T$. asahii fungemia during caspofungin treatment.

\section{Case presentation}

A 67-year-old male was admitted to our hospital because of fever, cough, and shortness of breath for 2 weeks. The patient received a renal transplant 8 years previously because of end-stage renal disease caused by diabetic nephropathy. The patient had hypertension and diabetes mellitus, which required antihypertensive therapy and insulin use, respectively. The patient also received immunosuppressive therapy. Two months before admission, regular follow-up showed $138 \mu \mathrm{mol} / \mathrm{L}$ creatinine values and normal chest computed tomography (CT) scan. Before admission, his antirejection therapy regimen included mycophenolate mofetil (500 mg in the morning and $750 \mathrm{mg}$ at night), tacrolimus ( $0.5 \mathrm{mg}$ daily), and prednisone ( $7.5 \mathrm{mg}$ daily). Upon admission, the patient presented with dyspnea, body temperature of $38.0^{\circ} \mathrm{C}$, respiratory rate of 28 breaths/ minute, oxygen saturation of $98 \%$ on $3 \mathrm{~L}$ via nasal cannula, blood pressure of 134/71 $\mathrm{mmHg}$, and a heart rate of 101 beats/minute. Physical examination revealed pulmonary moist rale and pitting edema in the lower extremities. The white blood cell count was $8.2 \times 10^{9}$ cells/L (89.5\% neutrophils), hemoglobin level was $114 \mathrm{~g} / \mathrm{L}$, and platelet count was $187 \times 10^{9}$ cells/L. Blood biochemistry revealed potassium ion and creatinine values of $6.59 \mathrm{mmol} / \mathrm{L}$ and $193 \mu \mathrm{mol} / \mathrm{L}$, respectively. C reactive protein was $199 \mathrm{~g} / \mathrm{L}$, 
and human immunodeficiency virus (HIV) test was negative. Chest X-ray revealed pleural effusion and bilateral airspace opacities consistent with pneumonia. The primary diagnosis was severe pneumonia. Thus, the antirejection regimen was adjusted to methylprednisolone ( $80 \mathrm{mg}$ every 12 hours). The patient empirically started intravenous imipenem/cilastatin (500 mg every 8 hours) and orally received trimethoprimsulfamethoxazole (160 mg of trimethoprim component twice daily). The patient also received continuous venovenous hemodialysis. However, the patient continued to deteriorate and required mechanical ventilation for respiratory failure. Three days after admission, the patient was transferred to the intensive care unit because of severe pneumonia accompanied with respiratory failure and heart failure. Chest CT scan showed discrete scattered patchy consolidation in both lungs (Figure 1). The patient received sputum and blood culture daily. Sputum culture showed the growth of Candida albicans for three tests. All blood culture tests yielded negative results from Day 1 to Day 8. Thus, the antimicrobial regimen was adjusted to intravenous teicoplanin (400 mg twice daily for 3 days; $400 \mathrm{mg}$ daily thereafter), imipenem/cilastatin (500 mg once every 6 hours), trimethoprim-sulfamethoxazole (160 $\mathrm{mg}$ of trimethoprim component twice daily), and caspofungin (loading dose, $70 \mathrm{mg}$; $50 \mathrm{mg}$ daily thereafter). Despite the aggressive therapy, the patient died 10 days after admission because of sepsis, resulting in multiple organ failure. The two sets of blood cultures and one sample of sputum collected on Day 9 showed the growth of T. asahii. This result was confirmed after the patient died using a Vitek 2 YST yeast identification kit (Vitek 2 YST, bioMerieux VITEK-2; Marcy l'Etoile, Durham, UK). Antifungal susceptibility test was performed using the microbroth dilution technique in accordance with the guidelines of the Clinical and Labora-

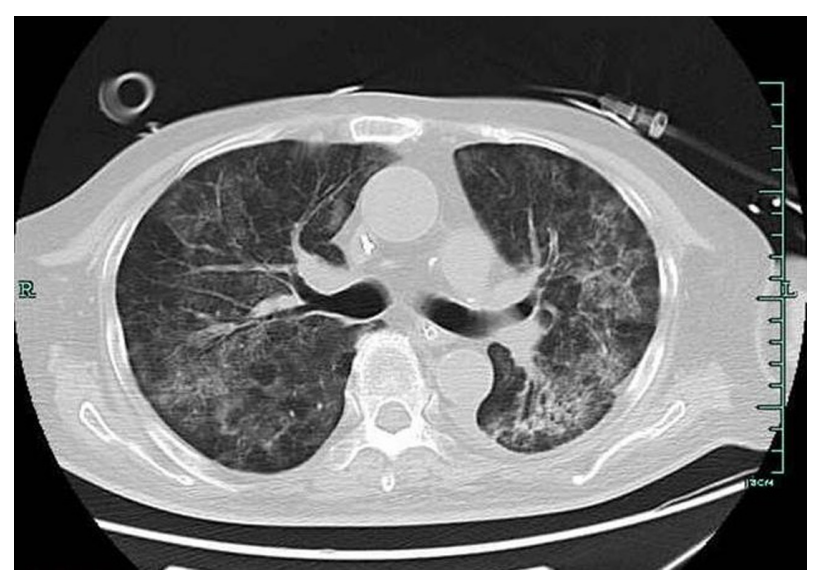

Figure I The chest computed tomography scan showed discrete scattered patchy consolidation in both lungs. tory Standards Institute. The results showed the following minimum inhibitory concentrations (susceptibility breakpoints): $0.5 \mathrm{mg} / \mathrm{L}(\leq 1)$ amphotericin $\mathrm{B}, 0.125 \mathrm{mg} / \mathrm{L}(\leq 0.125)$ itraconazole, $1 \mathrm{mg} / \mathrm{L}(\leq 8)$ fluconazole, $0.06 \mathrm{mg} / \mathrm{L}(\leq 1)$ voriconazole, and $4 \mathrm{mg} / \mathrm{L}(\leq 4) 5$-fluorocytosine.

\section{Discussion}

Over the last few decades, Trichosporon spp. have been increasingly recognized as opportunistic pathogens that can cause invasive infections, particularly in patients with underlying hematological malignancies, bone marrow transplantation, organ transplantation, extensive burns, HIV infection, and peritoneal dialysis. ${ }^{1}$ Systemic infections caused by Trichosporon spp. are frequently associated with poor prognosis. Six Trichosporon species, namely T. asahii, T. asteroides, T. cutaneum, T. inkin, T. mucoides, and T. ovoides, cause superficial, mucosa-associated, invasive infections. ${ }^{1}$ T. asahii is currently the predominant species in invasive Trichosporon infections. ${ }^{1}$

We report a patient with $T$. asahii fungemia and suspected pneumonia who presented an overwhelming sepsis during caspofungin therapy. To our knowledge, only a few studies have described Trichosporon infection in kidney transplant recipients; such infections are usually caused by $T$. beigelii and T. mucoides, and are associated with skin lesions, ${ }^{2,3}$ funguria, ${ }^{4,5}$ wound infection, ${ }^{6}$ and vascular anastomosis. ${ }^{7}$ T. asahii colonizes the urinary tract of renal transplant recipients. ${ }^{4} T$. beigelii funguria, which has been reported in renal transplant recipients, is usually benign and seldom associated with invasive infections. ${ }^{5}$ Only two cases of disseminated Trichosporon infection that causes skin lesions have been reported in renal transplant recipients. ${ }^{2,3}$ Mirza $^{2}$ reported a 45-year-old male who presented with malaise, fever, and multiple reddish nodules on the trunk and face 6 months after renal transplantation. Nodule biopsy culture confirmed T. beigelii infection. Analogously, Nettles et $\mathrm{al}^{3}$ reported a 64-year-old man complaining about fever, fatigue, malaise, and several pruritic papules on the lower limbs after renal transplantation; skin biopsy culture tested positive for T. mucoides. Fluconazole was effective in the two cases. The most typical skin lesions are multiple small nontender reddish-purple papules approximately $0.5 \mathrm{~cm}$ in diameter; with its progression, the nodule center becomes necrotic. ${ }^{2,3}$ However, the typical skin lesions were absent in our patient.

The common risk factors of $T$. asahii are granulocytopenia (particularly in hematological malignancies), organ transplantation, HIV infection, extensive burns, corticosteroid therapy, and peritoneal dialysis. ${ }^{1}$ In the present case, the patient 
had some risk factors for systematic fungus infection. These factors included organ transplantation, mechanical ventilation, broad-spectrum antibiotic therapy, continuous venovenous hemodialysis, and steroid therapy. However, neutropenia was not observed throughout the hospitalization.

The treatment for invasive Trichosporon infections remains difficult. Despite antifungal therapy, the mortality rate ranges from $42 \%$ to $87.5 \%{ }^{1}$ The optimal therapy regimen for trichosporonosis has yet to be identified. Echinocandins are ineffective against Trichosporon spp., ${ }^{8}$ with minimum inhibitory concentration values ranging from $16 \mu \mathrm{g} / \mathrm{mL}$ to $64 \mu \mathrm{g} / \mathrm{mL}$ for caspofungin from clinical isolates. ${ }^{3,9-12}$ The use of echinocandins leads to a significant selective pressure that is favorable for opportunistic fungi, including Trichosporon, with resistance to such agents; reports of Trichosporon infections in patients who are receiving micafungin or caspofungin have emerged. ${ }^{9,10}$ Increasing data indicated that amphotericin B has limited activity against Trichosporon spp. in vitro and in vivo. ${ }^{13}$ Moreover, in vitro susceptibility studies on amphotericin B for Trichosporon isolates are not always correlated with good clinical response. ${ }^{13}$ Triazoles are currently the drug of choice for the treatment of Trichosporon infections. The clinical experience with triazoles is encouraging. Previous cases reported successful treatment of disseminated trichosporonosis using voriconazole, posaconazole, and fluconazole. ${ }^{2,3,6,14}$ Recent studies have shown that voriconazole is highly active against $T$. asahii isolates in vitro and in clinical settings; these isolates include those with reduced susceptibility to amphotericin B, itraconazole, and fluconazole. ${ }^{14,15} \mathrm{~A}$ recent study with head-to-head comparison of five triazoles has shown that the most active is voriconazole, followed by itraconazole, posaconazole, isavuconazole, and fluconazole. ${ }^{16}$

Some clinical trials failed to treat disseminated T. asahii infection using amphotericin B or triazole alone. Thus, combined therapy has gained increasing attention for treating trichosporonosis. Echinocandins alone have little to no activity against Trichosporon spp. ${ }^{8}$ and are thus not recommended for trichosporonosis treatment; however, a combination of echinocandins with amphotericin B or azoles exhibits in vitro and in vivo antifungal effects. In vitro, the combination of micafungin/caspofungin and amphotericin B against $T$. asahii is more effective than using one drug only. ${ }^{11,12} \mathrm{~A}$ favorable response has been reported for the combination of amphotericin B and caspofungin therapy in a patient with untreated disseminated T. asahii infection; the patient was previously treated with amphotericin B alone and subsequent voriconazole therapy. ${ }^{17}$ Using a murine model with disseminated infection caused by T. asahii, Serena et a $\mathrm{l}^{18}$ found that combining micafungin with fluconazole significantly decreases the kidney fungal burden compared with administering either drug alone. Thus, combined antifungal therapy may be a potential strategy for treating disseminated trichosporonosis. Further research should be performed to investigate the in vitro and in vivo activities of antifungal drugs against Trichosporon spp.

\section{Conclusion}

Although funguria is benign, kidney transplant recipients are still at risk of invasive $T$. asahii infection even under antifungal therapy, particularly echinocandins. We describe a breakthrough $T$. asahii infection in a kidney transplant recipient from the People's Republic of China during caspofungin therapy. Clinicians should be aware that Trichosporon infections may develop in patients who are at risk of fungal infection, particularly when such patients develop symptoms and signs of an unexplained infection while undergoing echinocandin therapy. Triazoles, particularly voriconazole alone or in combination, are currently the drugs of choice for treating Trichosporon infections.

\section{Disclosure}

The authors declare no conflicts of interest in this work.

\section{References}

1. Colombo AL, Padovan AC, Chaves GM. Current knowledge of Trichosporon spp. and Trichosporonosis. Clin Microbiol Rev. 2011; 24(4):682-700.

2. Mirza SH. Disseminated Trichosporon beigelii infection causing skin lesions in a renal transplant patient. $J$ Infect. 1993;27(1): $67-70$.

3. Nettles RE, Nichols LS, Bell-McGuinn K, Pipeling MR, Scheel PJ Jr, Merz WG. Successful treatment of Trichosporon mucoides infection with fluconazole in a heart and kidney transplant recipient. Clin Infect Dis. 2003;36(4):E63-E66.

4. Netsvyetayeva I, Swoboda-Kopeć E, Paczek L, et al. Trichosporon asahii as a prospective pathogen in solid organ transplant recipients. Mycoses. 2009;52(3):263-265.

5. Lussier N, Laverdière M, Delorme J, Weiss K, Dandavino R. Trichosporon beigelii funguria in renal transplant recipients. Clin Infect Dis. 2000;31(5):1299-1301.

6. Sundaram M, Anandbabu K, Basu G, Devasia A, Tamilarasi V. Trichosporon surgical wound infection in a renal allograft recipient successfully treated with voriconazole. Transplantation. 2010;90(5): 588-589.

7. Fadhil RA, Al-Thani H, Al-Maslamani Y, Ali O. Trichosporon fungal arteritis causing rupture of vascular anastamosis after commercial kidney transplantation: a case report and review of literature. Transplant Proc. 2011;43(2):657-659.

8. Denning DW. Echinocandin antifungal drugs. Lancet. 2003;362(9390): 1142-1151.

9. Liao Y, Hartmann T, Zheng T, Yang RY, Ao JH, Wang WL. Breakthrough trichosporonosis in patients receiving echinocandins: case report and literature review. Chin Med J (Engl). 2012;125(14): 2632-2635. 
10. Bayramoglu G, Sonmez M, Tosun I, Aydin K, Aydin F. Breakthrough Trichosporon asahii fungemia in neutropenic patient with acute leukemia while receiving caspofungin. Infection. 2008;36(1):68-70.

11. Serena C, Mariné M, Pastor FJ, Nolard N, Guarro J. In vitro interaction of micafungin with conventional and new antifungals against clinical isolates of Trichosporon, Sporobolomyces and Rhodotorula. $J$ Antimicrob Chemother. 2005;55(6):1020-1023.

12. Li H, Lu Q, Wan Z, Zhang J. In vitro combined activity of amphotericin B, caspofungin and voriconazole against clinical isolates of Trichosporon asahii. Int J Antimicrob Agents. 2010;35(6):550-552.

13. Toriumi Y, Sugita T, Nakajima M, Matsushima T, Shinoda T. Antifungal pharmacodynamic characteristics of amphotericin $B$ against Trichosporon asahii, using time-kill methodology. Microbiol Immunol. 2002;46(2):89-93.

14. Falk R, Wolf DG, Shapiro M, Polacheck I. Multidrug-resistant Trichosporon asahii isolates are susceptible to voriconazole. $J$ Clin Microbiol. 2003;41(2):911.
15. Paphitou NI, Ostrosky-Zeichner L, Paetznick VL, Rodriguez JR, Chen E, Rex JH. In vitro antifungal susceptibilities of Trichosporon species. Antimicrob Agents Chemother. 2002;46(4):1144-1146.

16. Hazirolan G, Canton E, Sahin S, Arikan-Akdagli S. Head-to-head comparison of inhibitory and fungicidal activities of fluconazole, itraconazole, voriconazole, posaconazole, and isavuconazole against clinical isolates of Trichosporon asahii. Antimicrob Agents Chemother. 2013;57(10):4841-4847.

17. Bassetti M, Bisio F, Di Biagio A, et al. Trichosporon asahii infection treated with caspofungin combined with liposomal amphotericin B. J Antimicrob Chemother. 2004;54(2):575-577.

18. Serena C, Pastor FJ, Gilgado F, Mayayo E, Guarro J. Efficacy of micafungin in combination with other drugs in a murine model of disseminated trichosporonosis. Antimicrob Agents Chemother. 2005;49(2): 497-502.
Therapeutics and Clinical Risk Management

\section{Publish your work in this journal}

Therapeutics and Clinical Risk Management is an international, peerreviewed journal of clinical therapeutics and risk management, focusing on concise rapid reporting of clinical studies in all therapeutic areas, outcomes, safety, and programs for the effective, safe, and sustained use of medicines. This journal is indexed on PubMed Central, CAS,

\section{Dovepress}

EMBase, Scopus and the Elsevier Bibliographic databases. The manuscript management system is completely online and includes a very quick and fair peer-review system, which is all easy to use. Visit http://www.dovepress.com/testimonials.php to read real quotes from published authors.

Submit your manuscript here: http://www.dovepress.com/therapeutics-and-clinical-risk-management-journal 